\title{
Государственные платформенные сервисы: гражданское участие и институциональное доверие
}

\author{
А. Л. Гуринская ${ }^{1,2}$, И. А. Мещерякова ${ }^{1}$ \\ ${ }^{1}$ Санкт-Петербургский государственный университет, \\ ${ }^{2}$ Российский государственный педагогический университет им. А.И. Герцена \\ a.gurinskaya@spbu.ru
}

\section{Аннотация}

Внедрение цифровых технологий в государственное управление является устойчивой тенденцией последних лет: граждане могут не только получить государственные услуги в электронном формате, но и сообщить о волнующих их проблемах жизни района и города, поучаствовать в формировании местного бюджета и проголосовать за то или иное решение в области градостроительства, используя государственные платформенные сервисы. Вместе с тем нам пока мало что известно о том, насколько граждане готовы использовать имеющиеся платформы, и какие факторы детерминируют эту готовность. В настоящей работе на основе анализа данных, полученных в результате опроса 570 молодых граждан Санкт-Петербурга в 2019 г., показано, каким образом эта готовность связана с уровнем институционального доверия. Наряду с этим, оценивается значение и иных возможных предикторов гражданского участия на основе использования цифровых платформ, в том числе уровня доверия новым технологиям, степени политической вовлеченности и оценки эффективности гражданского участия. На основе полученных выводов даны рекомендации относительно совершенствования государственной политики в области развития цифровых платформ.

Ключевые слова: цифровое управление, государство как платформа, гражданское участие, институциональное доверие

Библиографическая ссылка: Гуринская А.Л., Мещерякова И.А. Государственные платформенные сервисы: гражданское участие и институциональное доверие // Государство и граждане в электронной среде. Выпуск 4 (Труды XXIII Международной объединенной научной конференции «Интернет и современное общество», IMS-2020, Санкт-Петербург, 17 - 20 июня 2020 г. Сборник научных статей). - СПб: Университет ИТМО, 2020. С. 20-31. DOI: 10.17586/2541-979X-4-20-31

\section{1. Введение}

Цифровые технологии за несколько десятилетий стали неотъемлемой частью нашей жизни. Сегодня сложно представить человека, который бы не пользовался мобильными устройствами, мессенджерами и приложениями, не имел бы опыта общения в социальных сетях. Приобрести необходимый товар или заказать необходимую услугу можно одним нажатием кнопки в телефоне или веб-браузере: от покупки продуктов и билетов до вызова няни или заказа такси. Государство также не остается в стороне и активно внедряет цифровые технологии 
в управленческую деятельность. Этот феномен получил наименования «электронное государство», «цифровое государство», «государство как платформа».

В широком смысле под электронным государством понимается «использование всех информационных и коммуникационных технологий от факсов до беспроводных гаджетов, которые применяются при государственном управлении», в более узком — это «деятельность, которая улучшает доступ граждан к государственной информации, услугам; увеличивает участие граждан в управлении и увеличивает удовлетворенность граждан государственным управлением»[1]. Одним из направлений деятельности электронного государства является создание и расширение платформенных сервисов для граждан. Одни из них («Госуслуги») предоставляют возможность получения государственных услуг в электронном формате. Другие («Твой бюджет», «Наш Санкт-Петербург», «Активный гражданин») призваны повысить уровень участия граждан в управлении и дать чиновникам возможность из первых уст оперативно узнать о проблемах, которые волнуют население, а также выяснить их мнение относительно возможных путей решения возникающих проблем и реализации планов.

Внедрение электронных сервисов началось сравнительно недавно. Некоторые из них уже завоевали популярность у граждан: многие оценили возможность обращения за услугами посредством интернета. Другие пока еще воспринимаются с осторожностью. На настоящий момент нам мало что известно о том, готовы ли граждане воспринять концепцию «государства как платформы» и активно вовлечься в процессы государственного управления на основе цифровых технологий. Также, малоизученным остается вопрос о тех факторах, которые детерминируют готовность людей стать «активными гражданами» электронного государства. Настоящая работа посвящена рассмотрению и эмпирической оценке значения этих факторов в российских реалиях. В литературе выделяются множество детерминант политического участия. В фокусе настоящего исследования находятся такие понятия, как институциональное доверие [2; 3, с. 127], доверие технологиям и [1; 4; 5], защита данных [6] и ряд других. С помощью анализа эмпирических данных мы ответим на вопрос о том, какие установки граждан имеют значение для решения задачи по активному вовлечению граждан в управленческую деятельность на цифровой основе.

\section{2. Платформенные сервисы}

Идея «государство как платформа» была сформулирована в 2016 году Центром стратегических разработок [7]. А уже в 2018 году был опубликован обстоятельный доклад, касающийся данной концепции, где говорится, что целью идеи государства как платформы является благополучие граждан и содействие экономическому росту, основанному на внедрении технологий. Приоритетом является создание условий, которые способствовали бы развитию человеческого потенциала, формированию комфортной и безопасной среды для его жизни, а также для создания и внедрения инновационных технологий. Государство как платформа предполагает, что с цифровой экосистемой будет взаимодействовать не сам человек, a его «цифровой двойник». Достоинством платформ является то, что они позволяют реализовывать функции управления не при помощи органов власти, а на основе платформенных решений [8]. Как следует из концепции, развитие государства как платформы предполагает не только пассивное получение государственных услуг онлайн, но и активное участие гражданина в управленческой деятельности. Платформенные решения развиваются не только на федеральном уровне, но также и в регионах. Так, в Санкт-Петербурге появились такие платформы как «Твой бюджет», «Наш Петербург» и др. Портал «Госуслуги» представляют собой «каталог государственных сайтов, в который включены официальные информационные

интернет-ресурсы, посвященные деятельности государственных ведомств» [9]. 
Зарегистрировавшись на данном портале, гражданин может получить различный спектр услуг от государственных организаций Российской Федерации. Спектр услуг зависит от того, какие данные гражданин предоставил и подтвердил ли он их лично в одном из государственных центров. Платформа «Твой Бюджет» была запущена в 2016 году в Санкт-Петербурге. Целью данного проекта было предоставление возможности жителям города напрямую поучаствовать в распределении городского бюджета. На сайте проекта говорится о том, что портал позволяет петербуржцам предложить свою идею о развитии городской среды, повлиять на эффективность расходования бюджетных средств и повысить качество городской среды [10]. Портал «Наш Санкт-Петербург» позволяет жителям города оперативно взаимодействовать с властями, направлять обращения о проблемах, связанных с ЖКХ, благоустройством, дорогами и тротуарами, незаконной торговлей и нарушениями миграционного законодательства. Кроме того, жители могут обращаться за дополнительной информацией, используя этот сайт [11]. На сегодняшний день существуют и иные платформы, предоставляющие гражданам возможность участвовать в делах государства. В дальнейшем можно ждать расширения как числа сервисов, так и их функциональных возможностей.

\section{3. Факторы, влияющие на участие граждан в процессах электронного управления}

Данная работа опирается на предыдущие исследования факторов, предопределяющих готовность граждан участвовать в управленческой деятельности (как офлайн, так и с использованием сетевых возможностей интернета). Как свидетельствуют многочисленные исследования, одним из наиболее значимых из этих факторов является уровень доверия, как межличностного, так и институционального. Т. Парсонс, например, рассматривает доверие в качестве механизма, который позволяет осуществлять взаимообмен ресурсами в обществе, которые необходимы для сохранения того самого общества. Иными словами, доверие является тем фундаментом, который позволяет функционировать обществу [12]. Р. Патнэм в своей теории социального капитала также выделяет доверие: оно является непременной составляющей капитала такого рода. Он полагает, что включение людей в деятельность общества, участие в различных гражданских ассоциациях повышает индивидуальную политическую грамотность, позволяет им добиваться коллективных, совместных целей. Люди, которые объединяются в ассоциации, делают это потому, что среди них больше доверия. Уровень вовлеченности граждан в общественную жизнь является базисом, который позволяет говорить о том, работает ли демократия, эффективна или не эффективна она. И, как итог, получается, что у Патнэма доверие есть необходимый фактор того, чтобы демократия сработала [2]. Таким образом, можно предположить, что доверие граждан институтам является необходимым фактором, который будет оказывать влияние на их желание участвовать в государственном управлении с использованием платформенных сервисов.

Использование платформенных сервисов государства подразумевает под собой работу с личными данными граждан. Получение той или иной услуги через платформенный сервис невозможно без передачи личных данных этому сервису. Поэтому Дж. Хиллер и Ф. Беланже посчитали одним из важных факторов, оказывающих влияние на готовность использовать платформенные сервисы, то, как государство собирает, хранит и обращается с личными данными граждан [6]. Д. Гилберт и П. Баллестрини в своем исследовании пришли к выводу, что защита информации пользователей один из важных факторов, которые оказывают влияние на желание использовать платформенные сервисы [13]. Технооптимизм - это уверенность в потенциале технологий, в их способности решить проблемы, стоящие перед человеком и обществом. По данным исследования, которое было проведено исследовательской командой 
МВШСЭН в 2016 году, россияне, в основном, относятся к внедрению новых технологий позитивно. Более $80 \%$ опрошенных полагают, что достижения науки и технологий делают жизнь проще и удобнее, порядка 70\% считают, что их ежедневная жизнь находится под влиянием технологических новшеств.

Приблизительно половина респондентов считают, что при помощи науки и технологий в будущем будет возможно разгадать все загадки человечества. Но вместе с тем, готовность к внедрению электронного судьи или беспилотного общественного транспорта, у россиян ниже, чем у европейцев (по данным исследования Евробарометр). То есть, россияне имеют более высокий обобщенный уровень доверия к инновациям. Когда же вопрос касается конкретных мер по внедрению тех или иных технологий, россияне менее склонны поддерживать эти меры [1]. Оценка уровня техноооптимизма помогает понять, насколько люди готовы к внедрению конкретных технологий (например, электронный судья), а не просто каких-то абстрактных технологических инноваций. Люди, которые участвуют в политической жизни, с большей вероятностью будут использовать электронные сервисы государства. Например, в исследовании, проведенном Р. Гоулдом, Ш. Голдфинчем и П. Хербисоном, было показано, что люди, которые голосуют на выборах, обращаются к политикам с предложениями, ищут различную информацию о государстве и государственных сайтах, с большей вероятностью будут активно использовать платформенные сервисы [14]. Иными словами, те люди, которые уже и так заинтересованы в политике и общественной жизни с большой долей вероятности будут пользоваться новой возможностью для участия. Авторы пришли к выводу, что электронные сервисы в настоящий момент времени не способны привлекать совсем аполитичных граждан, для решения этой задачи необходимы иные средства.

В ряде работ изучалась связь социо-демографических показателей с желанием участвовать в процессе управления на основе электронного взаимодействия. В исследованиях, проведенных на материалах Тайваня [15], а также Новой Зеландии и Австралии [16] было выявлено, что люди, у которых более высокий уровень доходов и уровень образования, с большей вероятностью будут пользоваться платформенными сервисами государства.

\section{4. Эмпирический анализ восприятия гражданами трансформаций в сфере уголовной политики}

\section{1. Метод и характеристики выборки}

Для реализации задач нашего исследования была разработана анкета, которая была апробирована на 20 респондентах в апреле 2019 г., после чего некоторые вопросы были изменены и уточнены. Выборка респондентов для исследования относится к типу стихийных выборок, что сказывается на репрезентативности результатов нашего исследования: полученные результаты не позволяют сделать выводы ни обо всей совокупности студентов Санкт-Петербурга, ни о более взрослом населении. Вместе с тем, учитывая пилотный характер настоящей работы, представляется, что наш подход является оправданным. В весеннем и осеннем семестрах 2019 г. был проведен анкетный опрос среди студентов двух крупных вузов Санкт-Петербурга. В данных вузах в совокупности обучается около 50 тыс. студентов, которые относятся к различным социально-экономическим группам населения, что давало широкие возможности для формирования выборки. В каждом из вузов на основании критерия доступности были выбраны 2-3 факультета, реализующих образовательные программы в области социальных и гуманитарных наук, а также искусства. На каждом факультете были получены согласия от 3 до 6 профессоров на то, чтобы провести анкетирование перед началом, на перерыве или после окончания их занятия, либо после окончания экзамена. Число студентов 
в каждом случае варьировалось от 12 до 50. В общей сложности для заполнения были розданы 600 анкет. В дополнение к этому, около 50 студентов заполнили анкеты в кафетерии и в зоне Wi-Fi (предварительно мы уточнили, не заполняли ли они анкету ранее). Из 650 анкет 579 были возвращены заполненными. Из них 570 анкет были пригодны для использования.

В ходе анкетирования студентам было предложено по шкале Лайкерта (от 1 до 7) оценить ряд суждений, где «1» соответствовало «совершенно не согласен», а «7» - «полностью согласен», также были вопросы с вариантами ответов «да» и «нет». Полученные в результате анкетирования данные были обработаны с использованием программы IBM SPSS Statistics. Для ответа на вопрос о том, какие факторы влияют на желание граждан взаимодействовать с платформенными сервисами государства, был проведен линейный регрессионный анализ по методу наименьших квадратов. Для создания шкал был проведен факторный анализ.

Социально-демографические характеристики респондентов представлены в Таблице 1.

Таблица 1. Социально-демографические характеристики респондентов (N=944)

\begin{tabular}{llcc}
\hline \multicolumn{1}{r}{ Переменная } & \multicolumn{1}{r}{ Значение } & $\mathbf{N}$ & \%* \\
\hline Пол & Мужской & 240 & 42,1 \\
\multirow{2}{*}{ Доход } & Женский & 321 & 56,3 \\
& Ниже среднего & 57 & 10,0 \\
& Средний & 231 & 40,5 \\
Выше среднего & 265 & 46,5 \\
\hline
\end{tabular}

*Сумма процентов распределений не равна 100 в связи с наличием в анкетах пропущенных ответов

Всего в исследовании приняло участие 321 девушек (56,3\%) и 240 юношей (42,1\%). Среди общего числа респондентов 203 (35,6\%) обучались на 1-2 курсах, 268 (47,0\%) на 3-4, а оставшиеся $88(15,4 \%)$ были студентами магистратуры или аспирантами. Большинство респондентов $(265 / 49,2 \%)$ указали, что доход их семьи является относительно высоким или высоким, а 231 человек (40,5\%) указали, что доход является средним. Лишь у 57 (10,3\%) респондентов доход их семьи ниже среднего.

\section{2. Зависимые и независимые переменные}

Зависимая переменная «Готовность использовать платформенные сервисы» состоит из суммы ответов респондентов на три вопроса, на которые им было предложено ответить, используя шкалу от 1 до 7, где 1 = «совершенно несогласен», а 7 = «абсолютно согласен» $(\alpha=.771)$. В таблице 2 представлены формулировки вопросов и распределение ответов на них. Из таблицы можно увидеть, что молодежь, в целом, скорее готова использовать платформенные сервисы для решения различных вопросов. Среднее значение по всем вопросам составило около 5, что несколько выше, чем нейтральное значение.

Независимые переменные, которые используются в данной работе это: доверие государству, политическая вовлеченность, защита данных, польза от использования платформ, технооптимизм, использование платформ. Респондентам также было предложено по шкале от 1 до 7 ( 1 = совершенно несогласен, а 7 = полностью согласен) оценить согласие с предложенными утверждениями. Шкала «Доверие государству» $(\alpha=840)$ построена из ответов на 2 вопроса: 1) Я думаю, что государственные органы учитывают мои интересы при принятии решений; 2) Государственные органы заслуживают доверия. Шкала «Политическая вовлеченность» $(\alpha=.502)$ состоит из суммы ответов (респондентам было предложено ответить «да» или «нет») на следующие вопросы: 1) Я регулярно обсуждаю политику со своей 
семьей/друзьями; 2) Я объединялся с жителями моего двора/района для того, чтобы решить какую-то проблему или проголосовать за то или иное решение; 3) Я обращался к чиновникам или в средства массовой информации в связи с проблемой, касающейся меня, моей семьи или моего района; 4) Я подписывал петиции, обращенные к государству, на негосударственных сайтах. Переменная «Защита данных» была построена из ответов на 1 вопрос, содержащий утверждение «Мои личные данные хорошо защищены, когда я размещаю их на государственных сайтах». Шкала «Польза от использования платформ» $(\alpha=.748)$ включает ответы на следующие вопросы: 1) Новые технологии позволяют государству больше знать о том, что беспокоит граждан; 2) Платформенные государственные сервисы позволяют людям принимать участие в улучшении жизни их района; 3) Интернет позволяет людям более эффективно сообщить о своем мнении чиновникам. Для построения шкалы «Технооптимизм» $(\alpha=.737)$ учитывались ответы на следующие 4 вопроса: 1) Если бы мне пришлось обратиться в суд, я бы предпочел, чтобы мое дело рассматривал электронный судья; 2) Я бы не возражал, если бы улицы патрулировали роботы-полицейские; 3) Я бы без сомнения воспользовался беспилотным автомобилем; 4) Я бы доверил роботу провести хирургическое вмешательство, если бы у меня возникла такая необходимость. В качестве контрольных переменных также были использованы возраст и доход.

Таблица 2. Готовность граждан использовать платформенные сервисы государства

\begin{tabular}{|c|c|c|c|}
\hline Переменная & $\mathbf{N}$ & $\begin{array}{c}\text { Среднее } \\
\text { значение }\end{array}$ & $\begin{array}{c}\text { Стандартное } \\
\text { отклонение }\end{array}$ \\
\hline $\begin{array}{l}\text { Я бы обратился в государственные органы через } \\
\text { государственный веб-сайт в связи с проблемой, касающейся } \\
\text { меня, моей семьи или благополучия моего города/района }\end{array}$ & 557 & 4,92 & 1,706 \\
\hline $\begin{array}{l}\text { Я бы обратился в государственные органы через } \\
\text { государственный веб-сайт в связи с проблемой, касающейся } \\
\text { меня, моей семьи или благополучия моего города/района }\end{array}$ & 557 & 5,30 & 1,654 \\
\hline $\begin{array}{l}\text { Я бы предпочел использовать веб-сайт или приложение для } \\
\text { получения государственных услуг, чем обращаться в } \\
\text { государственные органы лично }\end{array}$ & 558 & 5,53 & 1,589 \\
\hline
\end{tabular}

Таблица 3. Средние значения независимых переменных

\begin{tabular}{|c|c|c|c|c|c|}
\hline Переменная & $\begin{array}{l}\text { Аддитивный } \\
\text { индекс }\end{array}$ & $\begin{array}{c}\text { Среднее } \\
\text { значение }\end{array}$ & $\begin{array}{c}\text { Станд. } \\
\text { отклонение }\end{array}$ & $\begin{array}{c}\text { Мин. } \\
\text { значение }\end{array}$ & $\begin{array}{c}\text { Макс. } \\
\text { значение }\end{array}$ \\
\hline $\begin{array}{l}\text { Использование } \\
(\mathrm{N}=556)\end{array}$ & $\begin{array}{l}3 \text { компонента, } \\
\alpha=.771\end{array}$ & 15.75 & 4.09 & 3 & 21 \\
\hline $\begin{array}{l}\text { Политическая } \\
(\mathrm{N}=559)\end{array}$ & $\begin{array}{l}4 \text { компонента, } \\
\alpha=.502\end{array}$ & 1.5 & 1.13 & 0 & 4 \\
\hline Доверие государству $(\mathrm{N}=554)$ & $\begin{array}{l}2 \text { компонента, } \\
\alpha=.840\end{array}$ & 5 & 2.72 & 2 & 14 \\
\hline Защита данных (N=552) & 1 компонент & 3.37 & 1.68 & 1 & 7 \\
\hline Польза от платформ (N=551 & $\begin{array}{l}3 \text { компонента, } \\
\alpha=.748\end{array}$ & 13.2 & 3.98 & 3 & 21 \\
\hline Технооптимизм (N=551) & $\begin{array}{l}4 \text { компонента, } \\
\alpha=.737\end{array}$ & 13.88 & 5.87 & 4 & 28 \\
\hline
\end{tabular}

В Таблице 3 представлены данные о распределении ответов на эти вопросы. Мы видим, что уровень политической вовлеченности молодежи является достаточно низким. Также, нельзя 
сказать, что у граждан есть уверенность в том, что государство учитывает их интересы при принятии политических решений.

Уровень доверия государству, скорее, тоже можно охарактеризовать как низкий. Несмотря на то, что молодежь признает, что платформенные сервисы - полезный инструмент для того, чтобы донести свое мнение до чиновников и оказывать влияние на принятие ими решений, они обеспокоены тем, что их персональные данные могут быть недостаточно защищены. Вместе с тем, нельзя сказать, что они убеждены в том, что их информация под угрозой. Скорее, они не уверены в этом. Нельзя сказать, что молодые граждане безоговорочно доверяют технике и новым технологиям. Их отношение к электронному судье, роботам полицейским и хирургам, а также к беспилотным автомобилям также можно назвать амбивалентным. Данные свидетельствуют о том, что у граждан нет четкой позиции относительно того, насколько техника, выполняющая правоохранительные, медицинские и прочие функции, предпочтительна по сравнению с выполнением этих функций человеком. В следующем разделе мы рассмотрим, как установки по поводу государства, достоинств и недостатков платформ, а также уровень технооптимизма связаны с готовностью граждан использовать платформенные сервисы.

\section{3. Результаты}

Для оценки наличия зависимости между переменными использовался регрессионный анализ по методу наименьших квадратов. Результаты анализа представлены в Таблице 4.

Таблица 4. Бета коэффициенты и нормированный R-квадрат для регрессионного анализа, предсказывающего готовность граждан использовать платформенные сервисы

\begin{tabular}{|c|c|c|c|}
\hline \multirow{2}{*}{$\begin{array}{c}\text { Зависимая переменная } \\
\text { Независимые переменные } \\
\end{array}$} & \multicolumn{3}{|c|}{$\begin{array}{c}\text { Готовность граждан использовать } \\
\text { платформенные сервисы }\end{array}$} \\
\hline & B & SE & $\mathbf{t}$ \\
\hline Пол $($ женский = 0, мужской = 1) & $-0,9$ & 0,34 & $-2,65^{*}$ \\
\hline Доход & 0,04 & 0,25 & 0,17 \\
\hline Политическая вовлеченность & 0,48 & 0,15 & $3,19 * *$ \\
\hline Доверие государству & $-0,24$ & 0,07 & $-3,56 * * *$ \\
\hline Защита данных & 0,23 & 0,11 & $2,06^{*}$ \\
\hline Польза от платформ & 0,43 & 0,05 & $9,43 * * *$ \\
\hline Технооптимизм & 0,12 & 0,03 & $4,34 * * *$ \\
\hline Норм.R2 & & 0,3 & \\
\hline $\mathrm{F}$ & & $28.35^{\circ}$ & \\
\hline
\end{tabular}

Примечание: ${ }^{*} \mathrm{p}<.05 ; * * \mathrm{p}<.01, * * * \mathrm{p}<.001$

Полученные результаты, в целом, достаточно предсказуемы, а также согласуются с результатами предыдущих исследований. Готовность граждан использовать платформенные сервисы статистически значимым образом связано с их полом, уровнем политической вовлеченности, уровнем доверия государству, уверенностью в защищенности данных, пользой от платформ и технооптимизмом. Готовность граждан использовать сервисы не зависит от уровня их доходов. Так, респонденты, которые с оптимизмом относятся к технике $(\mathrm{b}=0,12 ; \mathrm{p}$ value <.001), а также считают, что с помощью платформ гражданам удастся более эффективно сообщать о своем мнении государству $(b=0,43$; $p$-value $<.001)$ с высокой долей вероятности будут готовы использовать платформы. Важным фактором является уверенность в защите данных на электронных площадках $(b=0,23$; p-value <.05). Более политически вовлеченные 
граждане (b=0,48; p-value <.01) более готовы использовать платформенные сервисы, нежели те, кто не вовлечен в политику. Если говорить об институциональном доверии, то здесь мы получили достаточно неожиданный результат: люди, которые менее склонны доверять государству $(\mathrm{b}=-0,24 ; \mathrm{p}$-value $<.001)$ более готовы пользоваться платформенными сервисами. Также исходя из полученных результатов анализа видно, что мужчины (b=-0,9; p-value <.05) c меньшей вероятностью будут готовы использовать платформенные сервисы. Судя по размеру полученных коэффициентов, более значимым эффектом обладает такой фактор, как убежденность в эффективности платформ.

У данной модели высокий объяснительный потенциал - независимые переменные объясняют 30 процентов вариации в распределении ответов на вопросы о готовности использовать платформенные сервисы (нормированный R2 = 0,30).

\section{4. Обсуждение результатов}

Данные нашего исследования показывают, что граждане готовы взаимодействовать с государством, опираясь не только на традиционные формы политического участия, но и на основе активно развивающихся платформенных сервисов.

Вместе с тем, пока их оценка собственной готовности скорее близка к нейтральной, чем однозначно утвердительной. Это может быть связано с тем, что платформенные сервисы появились в арсенале технологий государственного управления относительно недавно и являются новинкой, к которой граждане пока относятся с осторожностью. В дальнейшем интересно было бы выяснить, насколько уровень знакомства с отдельными платформами (например, «Госуслуги») и удовлетворенность своим опытом виртуального взаимодействия с государством на их основе, влияет на готовность пользоваться и иными сервисами. С другой стороны, уровень политической вовлеченности граждан, по оценкам нашего исследования, достаточно низок. Отсутствие желания участвовать в политической жизни общества, по всей видимости, распространяется не только на офлайн, но и на онлайн сферу.

Нас не удивили результаты, касающиеся влияния уровня доверия к технике и уверенности в защищенности персональных данных на готовность использования интернет-сервисов. В ряде работ ученые уже приходили к выводу, что для участия в платформенных сервисах пользователям необходимо знать, что их данные защищены [16, 17]. Наше исследование показало, что молодые граждане достаточно нейтральны в своих оценках потенциала новейших технологий (с которыми они пока еще даже не сталкивались - роботы-полицейские, беспилотные автомобили) и все же не до конца убеждены в безопасности своих данных на государственных сайтах. Вместе с тем, мы можем утверждать, что рост доверия к технологиям и повышение уверенности в защищенности информации не замедлит позитивным образам сказаться на уровне числа пользователей онлайн платформ.

Мы ожидали, что граждане, которые более склонны доверять государству, с большей вероятностью будут готовы использовать платформенные сервисы. Однако, полученные нами результаты говорят об обратном: те люди, которые меньше доверяют государству, более склонны использовать виртуальные формы общения с государством. Возможно, это связано с тем, что такие граждане рассматривают платформенные сервисы в качестве инструмента решения своих вопросов, причем инструмента, который более эффективен и прозрачен, чем традиционные методы взаимодействия с государством. Такие результаты были получены в исследовании, проведенном Р. Гоулдом, Ш. Голдфинчем и П. Хербисоном [14]. Они пришли к выводу, что люди, которые меньше доверяют государству, с большей долей вероятности воспользуются электронными сервисами, а не традиционными методами участия, такими, как обычное голосование. В дальнейших исследованиях интересным было бы выявить модерационный эффект доверия на иные факторы, детерминирующие 
участие. Рискнем предположить, что крайне высокий уровень недоверия будет все же способствовать снижению готовности граждан использовать платформы, взаимодействуя с уровнем уверенность граждан в том, что онлайн сервисы являются эффективным способом донесения мнения граждан до чиновников. Польза от платформ заключается в большей доступности и снижении барьеров для участия [18]. Наше исследование также показывает, что факт восприятия онлайн сервисов как платформ, которые предоставляют возможность гражданам принимать участие в жизни района, доносить до чиновников свою точку зрения по поводу различных общественных проблем, повышает готовность молодежи пользоваться ими. Причем, такая уверенность влияет на их политическую активность в виртуальном пространстве куда сильнее, чем озабоченность по поводу защиты данных или же доверие технологиям.

\section{5. Заключение}

Наше исследование показало, что молодые люди заинтересованы в использовании технологий в государственном управлении, в частности, в той сфере, которая расширяет их возможности участия в управленческих процессах. Вместе с тем, молодежь обеспокоена тем, как платформенные сервисы будут использовать и хранить их данные при работе, и это является значимым фактором, который влияет на их готовность использовать эти технологии, наравне с уровнем доверия к технике. Полученные нами результаты свидетельствуют о том, что уровень институционального доверия обратным образом коррелирует с желанием взаимодействовать с государством в интернете: низкий уровень доверия подталкивает людей к более активному использованию платформ. Вместе с тем, вряд ли этот вывод следует интерпретировать как сигнал для органов государственной власти к тому, чтобы отказаться от попыток завоевать доверие граждан, в погоне за показателями посещаемости государственных интернет-сервисов. Цифровизация экономики и государственного управления сейчас является одним из приоритетных направлений развития государственной политики. Поэтому исследования, посвященные гражданскому участию на основе использования электронных сервисов государства, необходимы для эффективного внедрения новых и улучшения уже работающих платформ.

Результаты нашего исследования показывают, что электронные платформы пока являются новым феноменом, достоинства которого не были в полной мере оценены молодыми гражданами. Если государство планирует продолжение курса по вовлечению граждан электронное в государственное управление, необходимо активнее доносить до пользователей информацию о существовании таких возможностей, демонстрировать их удобства, убеждать пользователей в безопасности тех данных, которые они оставляют на платформе. Государство имеет возможность вовлечь в пользование интернет-сервисами тех граждан, которые с интересом относятся к техническим новшествам и активно пользуются новыми технологиями интернет-коммуникации. Однако важным представляется и предоставление гражданам возможностей для политического участия не только в виртуальной среде - это будет способствовать их готовности регистрироваться на платформенных сайтах.

Нельзя не отметить отдельных недостатков настоящего исследования, которые связаны, прежде всего с его дизайном. Мы уже упоминали выше, что та выборка респондентов, которая была использована в нашей работе, не была случайной, в связи с чем мы не можем на основе наших данных предсказать готовность граждан из других социально-демографических групп взаимодействовать с государством в интернете. Кроме того, респонденты из нашей выборки относятся к категории людей со средними доходами и доходами выше среднего. Вследствие этого мы не можем сказать, будут ли респонденты, принадлежащие к иной социальной прослойке, разделять убеждения студенчества. В связи с этим представляется интересным 
дальнейшее проведение исследования с применением иной методологии, в частности, с использованием вероятностной случайной выборки.

За пределами нашего анализа остались и иные факторы, которые могут быть связаны с политической активностью в киберпространстве. Так, например, следует обратить внимание на значение таких факторов, как уверенность в возможности добиться общественных перемен, благодаря политическому участию, удовлетворенность работой государственных органах в различных социально-экономических областях, уровня межличностного доверия. Немаловажным обстоятельством, предопределяющим желание зарегистрироваться на платформенном сайте и принять участие в ее деятельности, может оказаться степень осведомленности о существовании платформ, удобство пользовательского интерфейса, уровень навыков использования новых технологий коммуникации. В дальнейшем имело бы смысл проверить гипотезы о значении этих факторов для готовности участвовать в государственном управлении на базе платформенных сервисов.

Работа выполнена при поддержке Российского фонда фундаментальных исследований, грант № 18-011-00756 А «Гражданское участие в условиях формирования цифрового правительства».

\section{Литература}

[1] Вахштайн В. и др. Публичный отчет по результатам социологического исследования поведенческих и институциональных предпосылок технологического развития регионов РФ / Степанцов П., Чурсина Ю., Бардина С. // РВК государственный фонд фондов и институт развития венчурного рынка Российской Федерации, 2016. URL: https://www.rvc.ru/upload/iblock/0e8/attitudes_to_technologies_and_innovations_in_Russia.pdf (дата обращения: 23.02.20).

[2] Putnam R. D., Leonardi R., Nanetti R. Y. Making democracy work: Civic traditions in modern Italy. Princeton University Press, 1994. 247 p.

[3] Гидденс Э. Судьба, риск и безопасность // THESIS. 1994. Вып. № 5. 127 с.

[4] Carter L., Bélanger F. The utilization of e-government services: citizen trust, innovation and acceptance factors // Information systems journal. 2005. Vol. 15, № 1. C. 5-25.

[5] Lee M. K. O., Turban E. A trust model for consumer internet shopping // International Journal of electronic commerce. 2001. T. 6, №. 1. C. 75-91.

[6] Hiller J. S., Bélanger F. Privacy strategies for electronic government. 2001. P. 162-198 // IBM Center for The Business of Government (E-Government Series). URL: http://www.businessofgovernment.org/sites/default/files/PrivacyStrategies.pdf (дата обращения 24.02.2020).

[7] Государство как платформа: люди и технологии (ВИДЕО) / РАНХиГС Российская академия народного хозяйства и государственной службы при Президенте Российской Федерации. URL: https://www.ranepa.ru/sobytiya/novosti/gosudarstvo-kak-platforma-lyudi-i-tehnologii/ (дата обращения 24.02.2020).

[8] Петров М. Государство как платформа. (Кибер) государство для цифровой экономики. Цифровая трансформация / Петров М., Шклярук М., Буров В., Шаров А. // Центр стратегических разработок, 2018. URL: https://www.csr.ru/upload/iblock/313/ 3132b2de9ccef0db1eecd56071b98f5f.pdf (дата обращения: 24.02.2020).

[9] О портале / Госуслуги. URL: https://www.gosuslugi.ru/ (дата обращения: 24.02.20).

[10] О проекте / Твой бюджет URL: https://tvoybudget.spb.ru/about (дата обращения: 24.02.20).

[11]О проекте / Наш Санкт-Петербург. URL: https://gorod.gov.spb.ru/ (дата обращения: 24.02.20). 
[12] Парсонс Т. О структуре социального действия. М.: Академический проект, 2000. 880 с.

[13]Gilbert D., Balestrini P., Littleboy D. Barriers and benefits in the adoption of e-government // International Journal of Public Sector Management. 2004. Vol. 17, № 4. P. 286-301.

[14]Goldfinch S., Gauld R., Herbison P. The participation divide? Political participation, trust in government, and e-government in Australia and New Zealand // Australian Journal of Public Administration. 2009. Vol. 68, № 3. P. 333-350.

[15]Hung S. Y., Chang C. M., Yu T. J. Determinants of user acceptance of the e-Government services: The case of online tax filing and payment system // Government Information Quarterly. 2006. Vol. 23, № 1. P.75-87.

[16]Zissis D., Lekkas D., Papadopoulou A. E. Competent Electronic Participation Channels in Electronic Democracy // Electronic Journal of e-government. 2009. Vol. 7, № 2. P. 195-208.

[17]Sharma G. E-Government, e-participation and challenging issues: a case study // International Journal of the Computer, the Internet and Management. 2014. Vol. 22, № 1. P. 23-35.

[18]Lee J., Kim S. Active citizen e-participation in local governance: do individual social capital and e-participation management matter? // 47th Hawaii International Conference on System Sciences. IEEE, 2014. P. 2044-2053.

\title{
State Platform Services: Institutional Trust and Civic Participation
}

\author{
A. L. Gurinskaya ${ }^{1,2}$, I. A. Meshcheryakova ${ }^{1}$
}

${ }^{1}$ St. Petersburg State University, ${ }^{2}$ Herzen State Pedagogical University of Russia

The introduction of digital technologies in public administration is a stable trend in recent years: citizens can not only receive public services in electronic format, but also report their concerns about district and city problems, participate in the formation of the local budget and vote for a particular decision in the field of urban planning, using public platform services. However, we do not yet know much about the extent to which citizens are willing to use existing platforms, and what factors determine this willingness. In this paper, based on the analysis of data obtained from a survey of 570 young citizens of St. Petersburg (Russia) in 2019, we will show how this willingness is related to the level of institutional trust. At the same time, we will assess the significance of other possible predictors of civic participation based on the use of digital platforms, including the level of trust in new technologies, the degree of political engagement, and the evaluation of the effectiveness of civic participation. Based on the findings, recommendations will be provided how to improve the state policy in the field of digital platform development.

Keywords: digital governance, state as a platform, civic participation, institutional trust

Reference for citation: Gurinskaya A.L., Meshcheryakova I.A. State Platform Services: Iinstitutional Trust and Civic Participation // The State and Citizens in the Electronic Environment. Vol. 4 (Proceedings of the XXIII International Joint Scientific Conference «Internet and Modern Society», IMS-2020, St. Petersburg, June 17 - 20, 2020). - St. Petersburg: ITMO University, 2020. P. 20-31. DOI: $10.17586 / 2541-979 \mathrm{X}-4-20-31$ 


\section{References}

[1] Vahshtajn V. i dr. Publichnyj otchet po rezul'tatam sociologicheskogo issledovaniya povedencheskih i institucional'nyh predposylok tekhnologicheskogo razvitiya regionov RF / Stepancov P., CHursina YU., Bardina S. // RVK gosudarstvennyj fond fondov i institut razvitiya venchurnogo rynka Rossijskoj Federacii, 2016. URL: https://www.rvc.ru/upload/iblock/0e8/ attitudes_to_technologies_and_innovations_in_Russia.pdf (data obrashcheniya: 23.02.20). (in Russian).

[2] Putnam R. D., Leonardi R., Nanetti R. Y. Making democracy work: Civic traditions in modern Italy // Princeton University Press, 1994. 247 p.

[3] Giddens E. Sud'ba, risk i bezopasnost' // THESIS. 1994. Vyp. № 5.127 c.

[4] Carter L., Bélanger F. The utilization of e-government services: citizen trust, innovation and acceptance factors // Information systems journal. 2005. Vol. 15, № 1. P. 5-25.

[5] Lee M. K. O., Turban E. A trust model for consumer internet shopping // International Journal of electronic commerce. 2001. Vol. 6, № 1. P. 75-91.

[6] Hiller J. S., Bélanger F. Privacy strategies for electronic government 2001. P. 162-198 // IBM Center for The Business of Government (E-Government Series). URL: http://www.businessofgovernment.org/sites/default/files/PrivacyStrategies.pdf.

[7] Gosudarstvo kak platforma: lyudi i tekhnologii (VIDEO) / RANHiGS Rossijskaya akademiya narodnogo hozyajstva i gosudarstvennoj sluzhby pri Prezidente Rossijskoj Federacii. URL: https://www.ranepa.ru/sobytiya/novosti/gosudarstvo-kak-platforma-lyudi-i-tehnologii/ (data obrashcheniya 24.02.2020). (in Russian).

[8] Petrov M. Gosudarstvo kak platforma. (Kiber) gosudarstvo dlya cifrovoj ekonomiki. Cifrovaya transformaciya / Petrov M., Shklyaruk M., Burov V., Sharov A. // Centr strategicheskih razrabotok, 2018 .

URL: https://www.csr.ru/upload/iblock/313/ 3132b2de9ccef0db1eecd56071b98f5f.pdf (data obrashcheniya: 24.02.2020). (in Russian).

[9] O portale / Gosuslugi. URL: https://www.gosuslugi.ru/ (data obrashcheniya: 24.02.20). (in Russian).

[10] O proekte / Tvoj byudzhet URL: https://tvoybudget.spb.ru/about (data obrashcheniya: 24.02.20). (in Russian).

[11] O proekte / Nash Sankt-Peterburg. URL: https://gorod.gov.spb.ru/ (data obrashcheniya: 24.02.20). (in Russian).

[12] Parsons T. O strukture social'nogo dejstviya // M.: Akademicheskij proekt, 2000. 880 s. (in Russian).

[13] Gilbert D., Balestrini P., Littleboy D. Barriers and benefits in the adoption of e-government // International Journal of Public Sector Management. 2004. Vol. 17, № 4. P. 286-301.

[14]Goldfinch S., Gauld R., Herbison P. The participation divide? Political participation, trust in government, and e-government in Australia and New Zealand // Australian Journal of Public Administration. 2009. Vol. 68, № 3. P. 333-350.

[15] Hung S. Y., Chang C. M., Yu T. J. Determinants of user acceptance of the e-Government services: The case of online tax filing and payment system // Government Information Quarterly. 2006. Vol. 23, № 1. P.75-87.

[16]Zissis D., Lekkas D., Papadopoulou A. E. Competent Electronic Participation Channels in Electronic Democracy // Electronic Journal of e-government. 2009. Vol. 7, № 2. P. 195-208.

[17] Sharma G. E-Government, e-participation and challenging issues: a case study // International Journal of the Computer, the Internet and Management. 2014. Vol. 22, № 1. P. 23-35.

[18] Lee J., Kim S. Active citizen e-participation in local governance: do individual social capital and e-participation management matter? // 2014 47th Hawaii International Conference on System Sciences. IEEE, 2014. P. 2044-2053. 